\title{
EL IDEAL MODÉLICO DE MUJER-MADRE EN LA CONSTRUCCIÓN DEL IMAGINARIO SOCIAL DEL ESTADO MODERNO EN ARGENTINA
}

\section{THE IDEAL MODEL OF MOTHER-WOMAN IN THE CONSTRUCTION OF THE SOCIAL IMAGINARY OF THE MODERN STATE IN ARGENTINA}

\author{
Melina Andrea Deangeli ${ }^{(1)}$ \\ María Eugenia Gastiazoro(2) \\ Melisa R. Sanchez ${ }^{(3)}$ \\ Universidad Nacional de Córdoba, Argentina
}

\begin{abstract}
Resumen: El trabajo se centró en el análisis de tres dispositivos que operaron como "tecnología de género" en la producción de subjetividades generizadas en Argentina: los proyectos educativos de masa y su relación con lo religioso, la Cárcel del Buen Pastor en la Provincia de Córdoba y la penalización del llamado "infanticidio". Se realizó un análisis cualitativo sobre los instrumentos legales y jurídicos (la ley de Educación Común 1420, el Reglamento de la Cárcel Correccional del Buen Pastor y decisiones judiciales en casos de infanticidio). Los resultados evidencian la función que tuvieron estos dispositivos en la gestión poblacional al consolidar una noción de mujer en base al ideal modélico de madre y esposa
\end{abstract}

(1) Profesora y Licenciada en Historia (Facultad de Filosofía y Humanidades de la Universidad Nacional de Córdoba. Abogada (Facultad de Derecho de la Universidad Nacional de Córdoba). Doctoranda en Ciencia Política (Centro de Estudios Avanzados, Facultad de Ciencias Sociales, Universidad Nacional de Córdoba). Centro de investigaciones de la Facultad de Filosofía y Humanidades (CIFFyH). Contacto: melideangeli@hotmail.com

(2) Doctora en Derecho y Ciencias Sociales por la Facultad de Derecho de la Universidad Nacional de Córdoba (UNC) (Argentina). Magister en Sociología por el Centro de Estudios Avanzados de la Universida Nacional de Córdoba (UNC). Abogada por la Facultad de Derecho (UNC). Becaria Pos-doctoral del Consejo Nacional de Investigaciones Científicas y Técnicas (CONICET-Argentina), Centro de Investigaciones Jurídicas y Sociales (CIJS) de la Facultad de Derecho (UNC). Contacto: megastiazoro@yahoo.com.ar

(3) Doctoranda en Estudios de Género por el Centro de Estudios Avanzados de la Universidad Nacional de Córdoba (CEA-UNC, Argentina). Licenciada en Trabajo Social por la Facultad de Ciencias Sociales de la UNC. Becaria Doctoral del Consejo Nacional de Investigacjones Científicas y Técnicas (CONICET-Argentina). Centro de Investigaciones Jurídicas y Sociales (CIJS) de la Facultad de Derecho (UNC). Contacto: meli.r.sanchez@gmail.com 
en distintos momentos y contextos socio-históricos de construcción del estadonación.

Palabras Clave: Tecnología de género, dispositivo, domesticidad, discurso jurídico, religión

Abstract: The article is focused on the analysis of three dispositives (dispositifs) that operated as "gender technology" in the production of gendered subjectivities in Argentina: mass educational projects and their relationship with the religious, the Buen Pastor Prison in the Province of Córdoba, and the penalty of the socalled "infanticide". A qualitative analysis was carried out on legal instruments (the Education Law 1420, the Regulation of the Correctional Prison of Buen Pastor and judicial decisions in cases of infanticide. The results show the function that these devices had in the population management by consolidating a notion of women based on the model ideal of mother and wife in different moments and sociohistorical contexts of nation-state construction.

Key Words: Gender technology, dispositive, domesticity, legal discourse, religion 


\section{A modo de introducción}

El presente trabajo recupera elementos de investigaciones que, desde diferentes recorridos, se aglutinan en torno a una dimensión en común que indaga en el modo en que diferentes dispositivos han operado como elementos productores de género en diferentes momentos y contextos socio-históricos. Nos centramos, específicamente, en el análisis de tres dispositivos que operaron como "tecnología de género" en la producción de subjetividades generizadas en Argentina: los proyectos de sistema educativo universal, la Cárcel del Buen Pastor en la Provincia de Córdoba y la penalización del llamado "infanticidio" durante el período de consolidación del Estado Nación. Sobre la figura de infanticidio se recogen decisiones judiciales recientes que permiten comprender la genealogía de la problemática en Argentina.

Entendemos la categoría mujer como un concepto en el que se fusionan y condensan una multiplicidad de significantes, herencia de diferentes tradiciones culturales y por lo tanto producto de contextos socio-históricos variados en el que, no obstante, a modo de continuidad, subyace la noción de mujer-madre-esposa como modelo. En este sentido, analizamos el modo en que diferentes dispositivos de control social y cultural han intervenido en la producción, reproducción y consolidación de la categoría. Para ello, recuperamos los aportes de Halperin y Acha (2000) que sostienen que la realidad histórica de los cuerpos es un producto de procesos culturales en los que el poder aparece como un factor decisivo puesto que la construcción de las subjetividades es paralela a la constitución de los géneros, procesos en los que se involucran clasificaciones, recortes de los cuerpos, instituciones como la educación y el castigo; que actúan través de múltiples operaciones de jerarquización y exclusión. De esta manera: "no es la anatomía en sí misma la que hace posible una experiencia histórica, sino las concepciones del momento que interpretan la carne y a través de las cuales se vive y siente a los cuerpos" (Halperin y Acha 2000:15). A los fines de indagar el modo en que la penalidad -materializada en Córdoba en la Cárcel del Buen Pastor-, el discurso jurídico y las instituciones educativas producen y comunican sentidos en relación al género, retomamos su planteo acerca de que "la mujer actual es una formación siempre neonata, una emergencia de un sistema de fuerzas e ideologías en vigencia" (Halperin y Acha, 2000:15).

En las próximas páginas, atravesadas por esta inquietud, abordamos cuestiones vinculadas a la rutina institucional que estructuró la vida cotidiana de las reclusas en la Cárcel del Buen Pastor, a los fines de recuperar las notas distintivas que asumió un proyecto de castigo específicamente dirigido a las mujeres. Siguiendo a Garland (2010) sostenemos que el castigo, en tanto artefacto cultural, construye y difunde nociones y significados culturales, operando activamente en la producción de subjetividades generizadas. El establecimiento correccional no 
fue ajeno a esta función y, en tanto institución de castigo, producía y comunicaba efectos culturales y sentidos sobre el individuo y la autoridad mediatizados por el género. Así, la rutina que ordenaba la vida de las asiladas prescribía tareas y actividades vinculadas a las labores domésticas, fuertemente ancladas en la ideología de la domesticidad (Nash 1994), contribuía a consolidar una noción de mujer en base al ideal modélico de mujer-madre.

En el campo de las instituciones educativas, los proyectos de universalización de la educación tuvieron como protagonistas a mujeres protestantes, desde donde el ideal de mujer-madre asumió una notoria presencia en el devenir en las tareas educativas y en las formas de ocupar los espacios públicos de las mujeres. Las mujeres, en lo educativo, tuvieron tareas constitutivas en la construcción del imaginario social del Estado Moderno, al mismo tiempo que fueron silenciadas de la historia oficial. No obstante, mientras que en sus tareas educativas reproducían valores hegemónicos del patriarcado y discriminatorias que dejaban afuera a gauchos e indígenas, al mismo tiempo ponían en tensión el status quo de la moral católica, tanto con sus prácticas religiosas protestantes, como por medio de la inserción como trabajadoras que impulsaba nuevos horizontes para las mujeres.

Esta condensación de sentidos en torno al ideal de mujer-madre se reproduce, no exenta de tensiones y resistencias, hasta nuestros días, y el discurso jurídico opera en este sentido como un elemento que perpetúa aquellas representaciones. La criminalización por medio de la figura atenuada del infanticidio en el siglo XIX se vinculó con la necesidad del Estado de regular la maternidad a los efectos de repoblar el territorio argentino (Calandria, 2017). En este sentido, "Ia clemencia y la preocupación por legitimar la maternidad eran vistas como señales de actitudes más «modernas»" (Ruggiero, 1994:227). En la actualidad, la eliminación de la figura del Código Penal Argentino en términos de homicidio atenuado implica un mayor punitivismo sostenido en representaciones que sujetan a las mujeres en imaginarios sociales que reproducen desigualdades en las que se articulan entramados de opresión (género, sexual, racial, clase). El peso de la ley cae sobre las imputadas, sobre todo cuando la imagen que el tribunal construye no coincide con la de la "buena madre y esposa".

\section{Tecnología de género y dispositivos de control de la subjetividad}

Central en nuestro análisis es el concepto de tecnología de género elaborado por de Lauretis $(1996 ; 2000)$. A partir de la crítica hacia el feminismo de la diferencia sexual -puesto que limita a los sujetos dentro de un esquema de la diferencia sexual dejando de lado los aspectos múltiples y contradictorios- el concepto de tecnología de género afirma que el sujeto está constituido en el género, pero no sólo a partir de la diferencia sexual sino a través de representaciones lingüísticas y culturales, 
en-gendrado en la experiencia de relaciones raciales y de clase (de Lauretis, 1996). La deconstrucción de la noción de género y diferencia permite mostrarla como una tecnología de sexo por medio de la cual se articula la instalación diferencial de los sujetos femeninos y masculinos. Sin embargo, también aparecen discursos que están "fuera de plano" (de Lauretis, 2000) y que permiten una deconstrucción del género. Siguiendo a Foucault (2008), en paralelo a la línea de su teoría de la sexualidad, de Lauretis aborda el género como tecnología del sexo, producto de variadas tecnologías sociales:

... pensar al género como el producto y el proceso de un conjunto de tecnologías sociales, de aparatos tecno-sociales o biomédicos es, ya, haberido más allá de Foucault, porque su comprensión crítica de la tecnología del sexo no tuvo en cuenta la instanciación diferencial de los sujetos femeninos y masculinos, y al ignorar las conflictivas investiduras de varones y mujeres en los discursos y las prácticas de la sexualidad, la teoría de Foucault, de hecho, excluye, si bien no impide, la consideración del género (1996, p. 8).

En este sentido, de Lauretis (1996) sostiene la paradoja foucaultiana: las prohibiciones y regulaciones relativas a los comportamientos sexuales, ya sean hablados por autoridades religiosas, legales o científicas, lejos de constreñir o reprimir la sexualidad, por el contrario la han producido y continúan haciéndolo en el sentido en que la maquinaria industrial produce bienes o comodidades y al hacerlo, también produce relaciones sociales. De ahí la noción de tecnología del sexo, que define como un conjunto de técnicas para maximizar la vida que han sido desarrolladas y desplegadas por la burguesía desde finales del siglo XVIII para asegurar su supervivencia de clase y su hegemonía permanente (de Lauretis, 1996). Estos discursos implementados a través de la pedagogía, la medicina, la demografía y la economía, fueron fijados o sostenidos por las instituciones del Estado y se tornaron especialmente focalizados en la familia; sirvieron para difundir e implantar, esas figuras y modos de conocimiento en cada individuo, familia e institución.

Sin embargo, también se plantea, desde otras posiciones términos que cuestionan estos discursos reguladores y creadores de sujetos determinados, lo que significa una construcción diferente del género. En este punto de Lauretis sugiere que:

para imaginar al género (varones y mujeres) de otra manera, y (re)construirlo en otros términos que aquellos dictados por el contrato patriarcal, debemos dejar el esquema de referencia centrado en lo masculino en el cual género y sexualidad son (re) producidos por el discurso de la sexualidad masculina. Pero los términos de una construcción diferente de género también 
subsisten en los márgenes de los discursos hegemónicos. Ubicados desde afuera del contrato social heterosexual e inscriptos en las prácticas micropolíticas, estos términos pueden tener también una parte en la construcción del género, y sus efectos están más bien en el nivel "local" de las resistencias, en la subjetividad y en la autorepresentación (De Lauretis 1996:36)

La mirada estructural de Federici (2011) permite entender el carácter construido de los roles sexuales en el mundo capitalista, llevada a cabo con la intervención estatal al redefinir las tareas productivas y reproductivas y las relaciones entre hombres y mujeres, en donde "la promoción de las fuerzas de la vida no resulta ser más que el resultado de una nueva preocupación por la acumulación y la reproducción de la fuerza de trabajo" (Federici, 2011:30). Resulta así de importancia entender la política del cuerpo, la que no se inscribe en la esfera de lo privado siendo el cuerpo tanto una fuente de identidad como una prisión (Federici, 2011). En este sentido la autora italiana incluye también el carácter represivo del poder desplegado contra las mujeres en el disciplinamiento de los cuerpos.

Abordar la construcción histórica de la mujer y el género mediante dispositivos de control social requiere, también, definir tales conceptos. Para ello retomamos a Agamben que utiliza la definición de Foucault para conceptualizar la noción de dispositivo entendiéndolo como un

conjunto resueltamente heterogéneo que componen los discursos, las instituciones, las habilitaciones arquitectónicas, las decisiones reglamentarias, las leyes (...) El dispositivo es la red que tendemos entre estos elementos (...) el dispositivo es una suerte de formación que, en un momento dado, ha tenido por función mayoritaria responder a una emergencia, el dispositivo siempre está inscrito en un juego de poder (Agamben s/f:1)

Asimismo, por control social entendemos "la estrategia tendiente a naturalizar y normalizar un determinado orden social construido por las fuerzas sociales dominantes" (Pegoraro; 1994), esta noción encierra dos dimensiones: una represiva y otra proactiva. Es necesario destacar, además, que la noción de control social no debe conducirnos a la idea de un supuesto consenso detrás del mismo, pues la noción remite necesariamente a las relaciones de fuerza y al conflicto que subyace a la construcción y producción del orden social (Daín, 2009).

\section{El género y el derecho: aproximaciones teóricas para el análisis}

Al analizar, en las diferentes secciones de este trabajo, instrumentos legales y jurídicos (el Reglamento que estructuró la vida cotidiana en la Cárcel Correccional del Buen Pastor, las sentencias judiciales en casos de infanticidio, la 
ley de Educación Común 1420) resulta pertinente recuperar, además la crítica que desde la perspectiva de género se formuló hacia el discurso jurídico y el derecho. En este sentido, retomamos el planteo de Pitch (2010), quien postula que

el derecho y los derechos, como cualquier otra dimensión de lo social, están atravesados por el género. A su vez, derecho y derechos construyen, disciplinándolo, el género de diversos modos al decir lo que es propio y legítimo del hombre y de la mujer, así como de las relaciones entre ellos. (...) El derecho y los derechos son por tanto sexuados (2010: 440)

En un sentido similar, Mendoza Eskola (2016) afirma que reflexionar sobre el derecho desde el feminismo implica asumir que el derecho, en tanto vertiente discursiva y procedimental de las relaciones de poder presentes en una sociedad, desempeña un papel decisivo en la perpetuación de los esquemas patriarcales de dominación. De este modo, los feminismos jurídicos comparten como nota transversal el cuestionamiento de la idea de una teoría jurídica neutral, objetiva e indiferente ante los fenómenos sociales, a la vez que se enfatizan el cúmulo de creencias e ideologías que, tras las normas aparentemente neutrales, intervienen en la consolidación del statu quo. El lugar del derecho en la consolidación del orden hegemónico constituye, por lo tanto, un punto nodal en la crítica feminista hacia el discurso jurídico. Así, la autora sostiene que

El derecho refuerza la rígida distinción público/privado y, al hacerlo, favorece la construcción estereotipada de una determinada "figura" de mujer. La crítica feminista a la distinción público/privado ha permitido demostrar la desigualdad derivada de la asignación de lo público a los hombres y lo privado a las mujeres, y remarcar que el hecho de ubicar a las mujeres en lo privado, ha permitido sustraerlas de lo público, en el sentido de la protección legal a sus derechos (....) el sistema normativo refuerza y reproduce roles y establece lugares para el quehacer de hombres y mujeres, asigna valores distintos a unos y otros, y, de esta manera, configura las identidades femenina y masculina. En este marco, la mujer es definida desde el único lugar legitimado por la norma: el privado (Mendoza Eskola, 2016, pag.143)

Desde Argentina, en un trabajo de reconstrucción de la relación entre derecho y teoría feminista, Mariana Sánchez (2009) señala tres momentos o etapas: el feminismo liberal, que irrumpe hacia la década del '60 y '70, que entiende al derecho como un sistema de normas que otorgan a las personas una valoración normativa diferenciada que reafirma las desigualdades sociales. Desde esta perspectiva, no son puestos en tela de juicio los principios que sustentan al 
derecho, como la objetividad o racionalidad, sino que lo que se cuestiona es el incumplimiento de tales principios en los casos que involucran a mujeres. Por ello, el objetivo principal de esta crítica feminista ha sido la igualdad entre hombres y mujeres la obtención de ordenamiento jurídico neutro y asexuado.

En el segundo momento del feminismo, se cuestionó el hecho de que el Derecho penal no sólo estaba cargado de sexismo, sino también de masculinidad, tanto en su estructura material de configuración como en los principios universales que lo sustentan, puesto que se encuentra compuesto por varones que lo ejecutan y administran, además de estar estructurado en base a valores masculinos en sentido cultural: objetividad, racionalidad, neutralidad, principios que se consideran típicamente masculinas, representando un elemento más del patriarcado. Este segundo momento del feminismo jurídico criticó, entonces, que las características de la cultura jurídica tendrán más elementos en común con la cultura dominante masculina que con las pautas culturales de la mujer. Por ello, la pretendida y defendida igualdad deja de ser un objetivo en sí misma (ya que, lejos de ser neutral, estaría construida desde una perspectiva masculina) y se comienza a reflexionar acerca de las diferencias entre los sexos. Según esta perspectiva, es imperativo que el Derecho reconozca las diferencias de género que contribuyan a redefinir su contendido ${ }^{(4)}$.

El tercer momento del feminismo, respaldado por las críticas posmodernas que niegan el carácter totalizador y universalizante de la esencia de las cosas, propone deconstruir las concepciones que se encuentran en la base de las clásicas dicotomías, para reconstruir en forma crítica conceptos como género, derecho, etc., remarcando la importancia de las subjetividades y diferencias, no sólo entre hombres y mujeres, sino también dentro del grupo de las propias mujeres.

\section{La domesticidad en el marco de la consolidación del Estado Nación}

A partir de la segunda mitad del siglo XIX, en el marco de consolidación del Estado Nación, es posible advertir en Argentina un proceso de modernización institucional que, entre otras cosas, implicó la expropiación social de las funciones que venían desarrollando desde prácticas asociacionistas diferentes organizaciones de la sociedad civil en favor del Estado (Oszlak, 2008). Desde las últimas décadas del siglo XIX, la República Argentina protagonizó un proceso de modernización acelerado que hallaría su momento culminante en la segunda década del siglo XX. La inserción en el mercado mundial tuvo múltiples consecuencias a nivel nacional: un gran crecimiento económico, la inversión de capitales extranjeros, la construcción

(4) Dentro de esta segunda oleada, denominada también feminismo radical, la autora citada ubica a Catherine McKinnon, quién naliza el derecho como parte de la estructura de dominación masculina surgida del sistema patriarcal. Siguiendo a Sánchez, encontramos que McKinnon además postula que las mujeres se encuentran inmersas en un contexto de dominación masculina que encuentra su origen en el poder que éstos tienen sobre el cuerpo de las mujeres. 
de vías férreas y la llegada masiva de inmigrantes. También creció el mercado interno y proliferaron industrias y talleres (Lobato 2007). El período comprendido por las últimas décadas del siglo XIX y las primeras del XX se caracterizó por la continuidad del modelo de acumulación, permaneciendo como eje de la actividad económica el modelo agro exportador y de producción primaria para la exportación.

Este cúmulo de transformaciones representó los signos de la modernidad cultural, modernidad que confluyó en la emergencia de nuevas conductas y actitudes (Barrancos 2010). La fuerte inmigración y el torrente de trabajadores extranjeros no sólo modificaron los aspectos relacionados a la oferta de fuerza de trabajo, sino también las relaciones de género (Lobato 2007). Es en el marco de dicho proceso de modernización que las mujeres ingresan al mundo del trabajo, y comienza un proceso de incorporación a la denominada "esfera pública". Sin embargo, en su investigación acerca de las trabajadoras en Argentina, Lobato señala que, aunque este proceso de modernización estuvo acompañado por una diversificación de las ocupaciones, fue un proceso casi exclusivo de los hombres, mientras que las mujeres permanecieron concentradas en aquellas actividades que se definían como tradicionales (costureras, tejedoras, modistas, domésticas, lavanderas, planchadoras). Paralelamente, creció el número de maestras y mujeres destinadas a la educación (resultado de la implementación de la ley 1.420). En otros casos, las mujeres se integraron al mundo laboral realizando actividades en el comercio o en las fábricas de ciudades como Buenos Aires y Rosario (como es el caso de las cigarreras).

En dicho contexto de consolidación del Estado Nación y en el marco de la creciente secularización que caracterizó a la Argentina de fines del siglo XIX, en un escenario donde la intervención y tratamiento de la cuestión social asumía gran preponderancia, es que se inscriben tanto las prácticas educativas de las mujeres protestantes y la concesión de la administración del correccional de mujeres a la orden del Buen Pastor en Córdoba. Las respuestas estatales que requería el encauzamiento de la cuestión social, condensaron en el desarrollo de instituciones orientadas a la educación, por un lado, y disciplinamiento, por el otro, de los sectores subalternos. En el caso de las mujeres, dichas instituciones reprodujeron y reforzaron los mandatos de género, operando activamente en el proceso de producción de subjetividades generizadas.

\section{La Cárcel del Buen Pastor como dispositivo productor de género}

La Cárcel correccional de mujeres en Córdoba fue producto de las gestiones que la Sociedad de Beneficencia había entablado con el gobierno municipal, entonces a cargo de la Cárcel del Cabildo, que reunía tanto a varones como mujeres. Tres décadas más tarde, bajo el gobierno de Manuel Pizarro, en 1892 se otorgaba la administración de la institución a la Orden del Buen Pastor, 
que entonces ejercía la administración de correccionales femeninas en otras latitudes de América Latina y Argentina. En el año 1900, la orden remite al gobierno provincial un modelo de reglamento que regiría la vida cotidiana en la institución, el que resulta aprobado sin mayor tratamiento ni modificaciones. El conjunto de rutinas y tareas que estructuraban la rutina institucional, conforme surge de las disposiciones reglamentarias, permite observar el modo en que en el tratamiento de la criminalidad femenina en la Córdoba finisecular condensó prescripciones ancladas en el ideal de domesticidad. El reforzamiento de los imperativos de género fue concebido, de este modo, como una herramienta para la "obra de regeneración moral" (Reglamento 1900) encarada por la orden religiosa.

Entre las rutinas cotidianas de la vida institucional, el Reglamento de 1900 estipulaba que las presas debían "hacer preparar diariamente, con las condenadas o procesadas mayores de edad, la comida para ellas mismas y para la Cárcel de Detenidos" (artículo 10 inciso 5). La prescripción de una actividad que obligaba a las reclusas a su alimento y el de los detenidos en la Cárcel de San Martín expresa el peso que la ideología de la domesticidad adquirió en las estrategias pensadas e implementadas por las religiosas en la tarea correccional. En este sentido el artículo refuerza la relación existente entre la mujer y la esfera privada, consolidando el papel de la mujer como madre y esposa, circunscribiendo las tareas que las mujeres realizaban dentro de la cárcel a la actuación en la esfera doméstica, al hogar y la familia. El ideal de la domesticidad estructuraba las rutinas de la Cárcel, prescribiendo tareas para la corrección de las reclusas que se encontraban fuertemente ligadas a las labores domésticas, y circunscribiendo de este modo la actuación femenina al ámbito del hogar. Así, el establecimiento reforzaba "el papel primordial de la mujer como madre y esposa..." (Nash; 1994).

Asimismo, el texto del Reglamento estipulaba que las presas recibirían una determinada instrucción en el establecimiento, fundamentalmente descrita como la enseñanza de "una profesión u oficio (...) como cocinera, mucama, etcétera." (Artículo 10). Estos elementos manifiestan que los aprendizajes exigidos guardan estrecha relación con el ideal dominante de mujer en las representaciones de la época, que la institución correccional contribuía a producir. Las tareas prescritas expresaban sentidos acerca del deber ser de la mujer; imponiendo un ideal modélico y así operaban como estrategias de producción de identidades de género fijas (Smart; 2000).

Angela Davis (2017), ha afirmado-en su estudio sobre las prisiones de Estados Unidos- que el género estructura el sistema carcelario y que las instituciones penales prescriben prácticas generizadas. En esta línea, podemos afirmar que la institución correccional del Buen Pastor se encontró fuertemente estructurada por el género. A partir de las estrategias y rutinas que prescribía para la regeneración de las reclusas, operó activamente en la consolidación de nociones y significados generizados sobre el individuo. Del mismo modo, merece destacarse que entre las destinatarias de la 
labor correccional se encontraban aquellas mujeres que, no habiendo cometido delito, sin estar procesadas o condenadas, eran ingresadas a la institución por orden de las autoridades domésticas (padre, marido o patrón), posibilidad ésta que se encontraba expresamente contemplada en el texto del Reglamento ${ }^{(5)}$.

Asimismo, dado su carácter de cárcel y asilo, la institución recibía a menores de edad ingresadas por los defensores de menores para "sustraerlas de la corrupción"(6). Recuperando, en este sentido, la propuesta de Garland (2010) del castigo como agente cultural que encarna y comunica sentidos sobre el individuo, permeados por el género, la Cárcel Correccional constituyó no sólo el lugar donde se preservara a la menor de la "corrupción"y en el que pasaban sus días las acusadas de transgredir las leyes, sino que también recibía a mujeres que eran remitidas en virtud de autoridades domésticas por transgredir imperativos de género, por desobedecer mandatos, para que allí se regeneraran mediante estrategias que incluían la realización de tareas del hogar. Otra causal en razón de la que fueron remitidas muchas mujeres de acuerdo a los registros de ingreso y egreso del Buen Pastor, fue el ejercicio de la prostitución clandestina, ingresadas por orden de la Asistencia Pública. Asimismo, el Estado municipal había dispuesto expresamente la posibilidad de que aquella mujer que quisiese abandonar el oficio, si deseaba podía internarse por el lapso de tres meses en el Asilo del Buen Pastor donde aprendería un oficio "honesto" (Lethinen y Salguero, 2017).

Mara Viveros (2008) afirma que la categoría de interseccionalidad pretende dar cuentas de la imbricación de las relaciones de poder, para analizar omisiones jurídicas y desigualdades concretas. Desde una perspectiva interseccional, es posible analizar el doble carácter de lugar para la "corrección" de las mujeres de la Córdoba de principios del XIX y de formadora en "oficios honestos". No sólo a las mujeres que ejercían el trabajo sexual se las preparaba para los servicios domésticos, sino que este constituía un objetivo general en la formación que la institución impartía a las presas, destacado por las religiosas en los informes remitidos al gobierno. Género y clase se imbricaban, de esta manera, en los objetivos regeneradores del Buen Pastor, construyendo género y formando mano de obra.

\section{La segunda madre. Educación y religión como dispositivo de orden y disciplinamiento}

A lo largo del siglo XIX se disputaron distintos proyectos educativos en el territorio argentino, motivados por la necesidad de homogeneización cultural, de garantizar mano de obra calificada y acorde al modelo civilizatorio del capitalismo

(5) Asimismo, este dato se condice con los registros del libro de ingresos y egresos de la Cárcel y Asilo, que exhiben gran cantidad de ingresos de mujeres producidos en virtud de pedidos de marido, padre o patrón.

(6) Archivo de la Legislatura de la Provincia de Córdoba, Compendio de Leyes y Decretos, Reglamento de la Cárcel correccional de mujeres y asilo de menores, 1900. 
occidental. Este proyecto de educación universal, por ende, da cuenta no sólo de una homogeneización cultural que invisibiliza las culturas originarias indígenas y diversidades migratorias, sino también de disciplinamiento y normalizador referenciado a modelos europeizantes. Puiggros (2003) señala que los diferentes proyectos se vinculan a intereses de actores sociales puntuales del momento:

1) la pedagogía liberal radicalizada, con una fuerte influencia de Rousseau y socialistas utópicos que fue traída por Moreno a estas tierras, donde se sostenía una educación antirracista, democrática en sus métodos, laica y anticlerical.

2) pedagogía federalista popular y liberal, quienes imaginaban una educación moderna apoyada y sostenida por la participación de la sociedad civil y la cultura de los pueblos. Esta pedagogía federalista fue promovida por los caudillos como Artigas y Urquiza.

3) la pedagogía de la generación del '37, y en particular la de Sarmiento, la cual era moderadamente liberal y partía de la exclusión de los indígenas y expresiones de cultura popular. Si bien rechazaba la herencia hispánica, proponía un modelo de enseñanza norteamericano de escolarización masiva.

4) Pedagogía liberal oligárquica que, encabezados por Rivadavia, quería la modernización del sistema educativo implementando estructuras e ideologías importadas de la experiencia de élite francesa. De mano de Rivadavia llega la propuesta del modelo Lancasteriano a Buenos Aires, el cual tuvo un fuerte apoyo de los sectores cristianos ya que uno de los materiales de educación era la Biblia.

5) la pedagogía tradicionalista colonial anti-independentista embanderada por los sectores pro-hispánicos de la Iglesia Católica, oponiéndose a la educación de los mestizos y los indígenas. Dicha corriente tuvo su núcleo directivo en Córdoba y luego se extendió al país.

Estas propuestas coexistían y se disputaban al interior de cada territorio provincial, siguiendo las tensiones y vaivenes de las disputas ideológicas y políticas de la época.

Puntualmente proponemos profundizar en el modelo sarmientista el cual también tuvo fuerte incidencia en la provincia de Córdoba, implementando un proyecto de formación docente dirigido a mujeres, las maestras normales. Este modelo fue tomado por Sarmiento en sus viajes a los Estados Unidos (1847) donde conoció la experiencia de Horace Mann como político y reformador del sistema educativo del Estado de Massachusetts y con compartía la idea de que el progreso 
capitalista requería de pensar en procesos educativos a largo plazo (Puiggros, 2003:48). A partir de entonces, entre 1869 y 1890 llegaron desde Estados Unidos 65 docentes (61 eran mujeres) para formar parte del proyecto de formación de docentes en las Escuelas Normales, empezando por la provincia de San Juan y posteriormente implementado en Córdoba, Catamarca y otras provincias.

Estas mujeres, llamadas "las hijas de Sarmiento", representaban una condición de mujer que se posiciona diferente en la sociedad argentina de mediados de siglo XIX. No sólo su condición de extranjeras norteamericanas, sino también por tener formación y desempeñarse laboralmente en el espacio extradoméstico. Sumado a esto, 60 de ellas profesaban el protestantismo y traían estilos de vida más liberales ${ }^{(7)}$, lo que generó marcada resistencia por parte de las familias católicas de las provincias. Este es un punto ha quedado como anecdótico en los relatos oficiales de la historia de la educación. Sin embargo es necesario notar que en un contexto de cuestionamiento del monopolio de la educación que estaba hasta entonces en manos de la Iglesia Católica Romana, en el que se están disputando proyectos de educación pública y masiva para la población, quiénes son formadoras de docentes también traen una formación cristiana, pero que al no tener una presencia institucional en dicho contexto histórico ${ }^{(8)}$, es minimizado. Al mismo tiempo, desde una mirada interseccional, no podemos dejar de poner en relieve el lugar de mujeres "blancas", con formación, en posición de educadoras lo cual las ubica simbólicamente en un lugar de referencia tanto para las maestras en formación criollas como para el resto de la población.

La implementación del sistema de formación de maestras normales significó la incorporación masiva de las mujeres al mundo laboral remunerado. Anzorena (2008) en sus análisis sobre la feminización de la tarea docente sostiene que al otorgar a las mujeres cualidades naturales e innatas de cuidado y educación, se suponía que no requerían grandes procesos de formación, por lo tanto, al hacerlo por vocación maternal, se constituyeron en mano de obra barata y flexible. Por lo tanto, "la feminización de la docencia produjo una redefinición del rol femenino: de maternidad biológica a maternidad social como desarrollo de los atributos maternales con los/as hijos/as no propios. En consecuencia, se creó una imagen del magisterio

(7) Yornet en sus registros refiere que Clara Gillies, oriunda de Saint Luis, estaba divorciada y los registros la recuerdan como una mujer vigorosa y enérgica. Clara llegó a Argentina en 1883 y fue vicedirectora de la Escuela Normal de San Juan y después fue trasladada a Rosario donde se volvió a casar. La autora también refiere que hubo conflictos suscitados por las diferencias de credos, en el que relata que la señorita Howard fue destinada a Córdoba y dejó en sus memorias relatado que una mañana encontró inscripto en la escuela "Esta es casa del diablo y puerta del infierno" (De Massi, 2007). En otras oportunidades, referentes del catolicismo como obispo Fray Esquiú debió mediar para que las familias católicas aceptaran que sus hijas/os asistieran a la escuela con estas docentes herejes (Yornet s/d).

(8) Si bien la presencia de protestantes de diferentes denominaciones data incluso de los procesos de invasión y colonización, en Argentina las primeras congregaciones formales aparecen en este período de entresiglo XIX-XX, la libertad de culto es reconocida en la Constitución de 1853, con sostén del Estado al culto católico apostólico romano. 
como prolongación de las cualidades femeninas naturales y fortaleció la continuidad del rol tradicional. Más allá del ingreso en el mundo del trabajo, se consideraba que era parte de la vocación maternal propia de las mujeres" (Anzorena, 2008:6)

A partir de la formación de las mujeres como maestras normales, las mujeres se incluyeron de manera masiva al mercado laboral, generando reestructuraciones en los horizontes familiares, vehiculizando posibilidades de movilidad en la estructura social y cultural, así también como generando incipientes formas de autonomía para las mujeres. Las mujeres que fueron formadas como docentes y se insertaron en la vida social desde este nuevo lugar, encontraron nuevas palabras que las enunciaban a ellas mismas, y que les brindaron la posibilidad de nombrar su mundo. Esto nos recuerda a Paulo Freire (2003), quien muchos años más tarde dirá que leer y nombrar el mundo crea conciencia e interrogantes y esos interrogantes llevan a búsquedas e interpelaciones que nos movilizan a la transformación.

Sin embargo, al mismo tiempo ellas mismas se presentaban como generadoras y reproductoras de estereotipos y normas sociales basadas en los géneros. La Ley de Educación Común ( $\left.\mathrm{N}^{\circ} 1420\right)$ sancionada por Roca en 1884, decreta una educación "obligatoria, gratuita, gradual y dada conforme a los preceptos de la higiene" (Art.2). En los contenidos curriculares lineamientos que facilitaron la gobernabilidad de la población, ordenando modos de proceder en las instituciones, estructurando y jerarquizando nuevas relaciones sociales y de autoridad, determinando también los modos de proceder de las y los/as docentes. Al mismo tiempo, organizaba la población, determinando posiciones y roles en el sistema social y familiar a partir de la distinción en contenidos por categorías de sexo-género.

Si realizamos una lectura de la ley en tanto dispositivo de poder, en el artículo $6^{(9)}$ se mencionan los contenidos elementales de la currícula, desde donde se estructuran lo que se espera que las niñas/mujeres y niños/varones reproduzcan: se necesita que unos (varones) tengan nociones básicas para insertarse en el mercado productivo de la época y en las milicias, consolidando la idea de unidad nacional, mientras que ellas (mujeres) garantizan la reproducción cotidiana de la existencia de la mano de obra, por medio de lo que Federici (2013) denomina trabajo reproductivo. Estos modos están vinculados a una estructura familia nuclear, heteropatriarcal y capitalista.

(9) Art. 6. El "mínimum" de instrucción obligatoria comprende las siguientes materias: lectura y escritura; aritmética (las cuatro primeras reglas de los números enteros, y el conocimiento del sistema métrico decimal y la ley nacional de monedas, pesos y medidas); geografía particular de la República y nociones de geografía universal; de historia particular de la República y nociones de historia general; idioma nacional; moral y urbanidad; nociones de higiene; nociones de ciencias matemáticas, físicas y naturales; nociones de dibujo y música vocal; gimnástica, y conocimiento de la Constitución Nacional. Para las niñas será obligatorio, además, el conocimiento de labores de manos y nociones de economía doméstica. Para los varones el conocimiento de los ejercicios y evoluciones militares más sencillos; y en la campaña, nociones de agricultura y ganadería. (las negritas no están en el original.) 
Un aspecto a destacar sobre los contenidos que las mujeres maestras normales debían inculcar es sobre las ideas de moralidad y buenas costumbres, con una perspectiva propia de la corriente higienista. Esta corriente proveniente de la medicina y la sociología positivista fue fuertemente abrazada por las políticas públicas de la época como consecuencia de las epidemias de cólera y fiebre amarilla de fines del siglo XIX con las corrientes migratorias. Por lo que educar en los hábitos alimentarios, higiénicos y sexuales fue una de las principales tareas que incluyó a las escuelas. Más allá del positivismo científico que comenzaba a imponerse, se puede inferir la influencia de los valores del cristianismo planteado en términos de discursos cientificistas. Esto es propio de lo que Dias Duarte (2006) llama un ethos religioso que se desempeña como sustrato de la vida social, pública, política, que nunca dejó de estar presente. El autor sostiene la importancia de "comprender lo religioso de las sociedades modernas, no desde una perspectiva nominal lineal, sino en el sentido amplio de una 'visión del mundo', una cosmología estructurante, reconociendo que los espacios de 'religiosidad' abarcan hoy muchos valores y comportamientos oficialmente "laicos' o, por lo menos, no confesionales" (Dias Duarte, 2006: 58, traducción propia).

De este modo hemos podido ver cómo las mujeres han sido parte constitutiva del modo de ser mujeres en esta sociedad moderna a través del dispositivo educativo, tanto en el modo de inserción en la vida pública de la sociedad moderna como en la transmisión y reproducción de las normas de género. Marcela Lagarde (2005) define el lugar de las mujeres en la sociedad patriarcal como cautiverios en los que las mujeres son definidas políticamente desde las relaciones de poder, privándoles de determinadas libertades. Desde esta perspectiva, entendemos que la articulación del dispositivo educativo con el trasfondo religioso e higienista habría propiciado un disciplinamiento de los cuerpos de las mujeres, reafirmando la vinculación de la condición de ser mujer con tareas de cuidado tanto no remunerado como remunerado. Esto significa, asimismo, garantizar la gobernabilidad de la población en su conjunto, el establecimiento de un determinado orden basado en los géneros para cada actor social como parte del proyecto civilizatorio occidental moderno.

\section{La sentencia como dispositivo normalizador de las mujeres en casos de infanticidio}

\subsection{Control de la sexualidad de las mujeres}

Aunque la figura de infanticidio se encuentre derogada en el sistema jurídico Argentino, las decisiones judiciales actuales en casos donde una mujer es sentenciada por la muerte de un hijo recién nacido, retrotraen a esta figura al replicarse ciertos sentidos y construcciones sociales, acentuándose en un mayor punitivismo. De acuerdo a Salvatore (2010), la cultura legal estatal es la cultura del orden institucional, por medio de la cual se construyen categorías que 
clasifican y encasillan a sujetos delincuentes, implicando una subalternización de determinados sujetos sociales, de acuerdo a desigualdades de clase, género, raza, educación, entre otras. Esto significa que: "legislación, jurisprudencia, doctrina legal y práctica judicial y policial constituyen un vasto espacio discursivo donde se generan y reproducen las nociones dominantes sobre orden social, delito, desviación y pena..." (Salvatore, 2010:41).

La mujer en el imaginario jurídico de la América colonial se construyó sobre los criterios que históricamente clasificaron a las mujeres occidentales, sostenida en una "naturaleza femenina" que significó la imposición del control de los cuerpos (Vasallo, 2007). En este sentido, la sexualidad debía tener lugar dentro del matrimonio y con el exclusivo objetivo de la procreación. El comportamiento contrario suponía poner en jaque la finalidad natural asignada a la mujer: ser esposa y madre, el honor familiar (sustentado en el comportamiento "casto" o "virginal" de esposas e hijas), y la integridad del patrimonio; en definitiva, el "orden social" (Vasallo, 2007:494).

El infanticidio se reguló a finales del siglo XIX, en el primer Código Penal de Argentina en 1887. Se estableció como el homicidio de un niño recién nacido por parte de su madre, con el fin de esconder el deshonor, siendo la pena muy leve en comparación a otros tipos de homicidios: "esta indulgencia reflejaba, en parte, el estadio de desarrollo de Argentina y la influencia de los códigos legales y modelos culturales extranjeros. La clemencia y la preocupación por legitimar la maternidad eran vistas como señales de actitudes más «modernas»" (Ruggiero, 1994:227).

Bajo la conceptualización de la honra femenina se sostuvo en discursos históricamente producidos bajo el ideario hetero-patriarcal donde, "el ejercicio de la sexualidad se plantea como válido dentro del matrimonio y con fines de procreación y toda mujer que transgredetales representacionesy valores considerablementearraigados en el imaginario social deja de ser una mujer "honesta" (esposa-madre-asexual) para convertirse en "deshonesta" (mujer-prostituta-sexual)" (Martinetti 2013:226).

Es decir que las penas estaban reducidas y se hacía hincapié en entender la situación de las mujeres que lo cometían. Sin embargo, esa consideración se realizaba bajo una trama de mecanismos y estrategias de disciplinamiento (Ruggiero, 1994) dirigidas a resguardar el sistema sexo-género patriarcal donde las acciones de las mujeres se referenciaban en la afección que los varones podían tener en su integridad moral y status social (Maritnetti, 2013).

En la provincia de Córdoba, (Argentina) la problemática de mujeres acusadas en el marco de un hecho de muerte de un bebé recién nacido, vuelve a ponerse en el debate público a partir del caso de Daiana G. ${ }^{(10)}$, que fue detenida

(10) El día 21 de Diciembre de 2016, la Legislatura de la Provincia de Córdoba aprobó una declaración 
(encarcelada) en el año 2016 por supuesto homicidio de su hija recién nacida, y liberada en el año 2017 antes de tramitarse su juicio, al quedar evidenciado que el hecho ocurrió bajo la violencia machista de su pareja. A finales del año 2017 fue juzgada ante la Cámara Penal correspondiente por medio de un juicio oral llevado a cabo en presencia de jurados populares. También fue sentenciada su pareja, siendo ambos condenados por el homicidio culposo de su hija, imponiéndoseles la pena de tres años de prisión en forma de ejecución efectiva y costas. Cabe destacar que el tribunal determinó no hacer efectiva la pena sobre Daiana, ya que no estaba firme la resolución y no habían variado las condiciones por las que oportunamente se le otorgó su libertad, además se encontraba con un embarazo en curso.

El juicio oral fue sobre ambos, sin embargo cabe destacar que la sentencia se construyó sobre la historia de vida de la mujer imputada, quien es expuesta e interpelada como madre y esposa ${ }^{(11)}$, tomando como eje del debate el ejercicio de su sexualidad tanto dentro como fuera de su relación matrimonial de parejaconcubino. Daiana llega a la primera audiencia, excarcelada, testimoniando que ella ha sido llevada a parir a un sitio baldío-descampado coaccionada por su pareja quien duda de su paternidad biológica, y acciona a su vez, llevándose a la niña recién nacida quien muere de hipotermia. Sin embargo, tal relato será puesto en duda y descreído por los jueces como por la mayoría de los jurados. Para el fiscal de cámara como para el tribunal en mayoría, la hipótesis real fue la siguiente: hubo un pacto entre ambos quienes no deseaban ese bebé, ante la sospecha de que había sido concebido con otro hombre, como tal decidieron hacer el parto en el baldío, para luego entregar a la niña a un tercero, desestimando su posible muerte que luego ocurrió.

En Argentina, al haberse derogado la figura de infanticidio del Código Penal en el año 1994, este tipo de hechos es juzgado bajo la tipificación legal de homicidio calificado por el vínculo, condenado con pena de prisión perpetua. De acuerdo a los datos de las sentencias obtenidas sobre juicios realizados con jurados populares, se observa que a lo largo de diez años (2006 y 2016) diez mujeres fueron juzgadas por el hecho (consumado o no) de la muerte de su hija recién nacida, tipificado en los términos de homicidio calificado por el vínculo, en las distintas elevaciones a juicio. El caso de Daiana, tuvo dos cuestiones de importancia particular a destacar, primero fue liberada ante la acción de su defensa, en la que intervinieron distintas

en la que estableció su "preocupación por la situación de la joven Dayana Gorosito (víctima de violencia de género), detenida hace 150 días, bregando por la pronta resolución de su caso que conmovió a la opinión pública".

(11) La figura de infanticidio se incorpora en el primer Código Penal de Argentina (sobre la base del proyecto de Tejedor), que empieza a regir en 1887. Es derogada por la ley 17.567 (1968), regresa con la ley 20.509 (1973), vuelve a desaparecer con la ley 21.338 (1976) y reaparece a partir de 1984, con las reformas del texto ordenado del Código (decr.3992/84), para ser derogada finalmente por la ley 24.410 dictada en el año 1994 (Creus, 1998). 
organizaciones y colectivos de mujeres que la acompañaron ${ }^{(12)}$, declarando la violencia machista bajo la cual se encontraba cuando el hecho ocurrió. En este sentido, la comunidad organizada en torno al caso había tomado posición en su defensa también, alegando la violencia de género. Segundo, no fue la única imputada, sino también su pareja en el momento del hecho, quien era el padre de la recién nacida. Esto último resulta de importancia porque en la sentencia, son dos imputados, sin embargo, el reproche y responsabilidad en el discurso judicial recae sobre ella. La referencia al ejercicio de la sexualidad Daiana, remite a la vigilancia histórica sobre el ejercicio de la sexualidad de las mujeres. Se insiste en el pliego de preguntas a los testigos de la causa sobre su infidelidad y sus relaciones con otros hombres. Esto se observa en la siguiente testimonial:

“(...) recordó haber hablado con él acerca de una relación amorosa con su cuñada. Que tenían relaciones sexuales y que se cuidaban. También recordó que Jesús dijo verse sorprendido porque había descubierto otra cuestión amorosa de Daiana con un sobrino u otro pariente de él...Que a raíz de esto, se practicaron nuevos allanamientos en búsqueda de elementos que pudieran servir para la causa, ya que hasta ese momento no se sabía la paternidad del bebé ni se tenía certeza del lugar donde se había producido el alumbramiento" (Fallo: "G., D. T. y O., J. L., de la Cámara en lo Criminal 12a, con fecha: 16/02/2018).

Esto última evidencia cómo la antigua noción de salvaguardar el "honor" de las mujeres presente en la figura de infanticidio derogada por concebir hijos fuera del matrimonio, persiste categorizado en términos de ejercicio de la sexualidad, en el discurso de la sentencia.

\subsection{Violencia de género}

Una de las cuestiones que se revelan en este tipo de hechos, apreciados como aberrantes desde la opinión pública, es que el encuadre de los mismos requiere de una perspectiva feminista y de género que considere conectar los hechos con la desigualdad e inequidad social en la que se inscriben las mujeres como miembros de la sociedad (Femenías y Soza Rossi, 2009) la que se impone por medio de distintos tipos de violencias: sexual, física, psíquica o económica. En el caso presentado, así lo exigió la defensa, quien en un principio logró la excarcelación de la imputada, y sostuvo los argumentos en el alegato del juicio oral, sin embargo, no pudo hacer mella en la postura del fiscal de cámara como en la decisión de los jueces técnicos, junto a cuatro jurados. El fallo estuvo divido, en disidencia dos jurados entendieron que Daiana tenía que ser absuelta ya que fue

(12) En el Encuentro Nacional de Mujeres realizao en el año 2017 en Argentina, este caso fue presentado en el Tribunal Ético de Justicia Feminista. 
coaccionada por su pareja para realizar el hecho. Por el contrario, otros dos jurados entendieron que la absolución debía ser para la pareja de la imputada.

Sin embargo, hay que estar alertas, ante un discurso legal informado en teoría de género por medio del cual se asigna a las mujeres lugares de la debilidad y ausencia de poder, sustrayéndole la posibilidad de acción y violencia al señalarlas como víctimas pasivas, relegando las acciones empoderantes que implican la descalificación del sujeto en el pedido de justicia (Trebisacce, 2016). Como tal, la condición de víctima se concibe como un relato que determina toda la verdad de la situación -obstruyendo la complejidad de la realidad como otras potencialidades de los sujetos- y no como una estrategia frente a una sociedad patriarcal, racista y capitalista (Trebisacce, 2016).

En este sentido, el rechazo de los jueces y fiscal en identificar la violencia de género en la cual se encontraba sometida la imputada y que determinaba que su voluntad estaba viciada, es fundamentado en que no verifican en la interpretación de las pruebas su existencia y en todo caso entienden que hasta ha podido planificar el hecho. Cuestionan el lugar de debilidad y ausencia de poder como víctima pasiva, y es en el ejercicio de la sexualidad donde sostienen la justificación para descalificar las declaraciones sobre los hechos que vivió la imputada.

\subsection{El deseo materno}

Por último, hacemos referencia a la exigencia del deseo materno en el hecho a los efectos de darle credibilidad a la palabra de la mujer imputada y sometida a proceso. En este caso se observa que el fiscal al momento de analizar los hechos e incriminar a Daiana, la juzga por su actitud "fría", que él observó en su declaración presencial en el desarrollo del juicio oral, la que entiende que no se corresponde con la falta de dolor que debería mostrar por la muerte de su hija. A lo cual ella respondió:

"que el Fiscal en una parte está mal porque no la conoce. Que estuvo un año presa en la cárcel y sílloró, que tuvo su duelo. Que sí tiene sentimientos y no es necesario que venga acá a llorar delante de gente que no conoce, que lo hace en la intimidad. Que sólo ella sabe lo que pasó y vivió. Sí quiere a Romina y ella misma eligió su nombre. Que es cuanto desea declarar" (Fallo: "G., D. T. y O., J. L.", de la Cámara en lo Criminal 12a, con fecha: 16/02/2018).

Condice con lo que Ruggiero (1994) observa en su investigación historiográfica sobre condenas a mujeres infanticidas en el período 1871-1905, en Buenos Aires, en la que revela cómo en una época en la cual la sociedad empieza a insistir en la importancia de la maternidad y los niños, propio de una sociedad "moderna", las mujeres imputadas de infanticidio necesariamente tenían que 
mostrar algún sentimiento materno, ya que "el fracaso de una mujer en cumplir con su papel de madre al ser empujada por un profundo sentido del honor podía ser tolerado; pero su rechazo del sentimiento asociado con la maternidad, no" (Ruggiero, 1994:232).

Lo analizado hasta aquí permite mostrar a partir de un caso reciente y por medio de la sentencia judicial como dispositivo, la actualización de determinadas regulaciones sociales históricamente construidas sobre las mujeres desde la América colonial y en continuidad con la constitución del Estado-nación. El discurso jurídico sujeta a las mujeres en el hetero-patriarcado por medio del control de la sexualidad sostenido en representaciones sociales de la "buena madre y esposa" y en última instancia en la victimización de las mujeres como determinante de la legitimación en el acceso a la justicia.

\section{Reflexiones finales}

La trama de poder que se entreteje entre el dispositivo educativo de masas con las corrientes religiosas cristianas hegemónicas (catolicismo) y no hegemónicas (protestantismo), y el positivismo científico en las corrientes higienistas, habría propiciado una red de poderes que no sólo disciplina los cuerpos de las mujeres reafirmandola vinculación dela condición de sermujercontareas decuidadoy delatarea educativa como extensión de su instinto materno; sino que también es un dispositivo que dispone posiciones y un determinado orden generizado para la sociedad en su conjunto. En este proceso se va configurando, considerando la dimensión realizadora de las normas, cómo se debe ser una buena mujer en este contexto, en particular una matriz de la participación de las mujeres en el espacio público.

El discurso jurídico se revela como un dispositivo de control de los cuerpos de las mujeres que las subalterniza de acuerdo a dimensiones de género, raza, educación y clase. En este sentido, recae sobre determinadas sujetas definidas como delincuentes generando y reproduciendo las categorías del sistema sexo/género que implican poner a las mujeres en el orden de la reproducción de la vida social.

El abordaje histórico de las instituciones analizadas muestra la tarea central que tienen en la dimensión realizadora del género en tanto que legitiman determinadas conductas y procederes y rechazan o penalizan otros, en base a los postulados del patriarcado heteronormativo. Los distintos dispositivos han operado (y operan) por medio del control de la sexualidad como elementos productores de género (tecnología de género) en distintos momentos y contextos socio-históricos de construcción del estado-nación. La gestión poblacional se configuró sobre las categorías de "buena madre" y"esposa" en el marco de la división sexual del trabajo capitalista, por medio de la separación y localización diferenciada y subordinada de las mujeres dentro de una lógica binaria de lo público y lo privado. 


\section{Bibliografía}

AGAMBEN, Giorgio (s/f) ¿Qué es un dispositivo? Disponible en: http://ayp.unia.es/ r08/IMG/pdf/agamben-dispositivo.pdf

ANZORENA, Claudia. (2008). "La participación de las mujeres en el proceso de formación del Estado Nacional en Argentina de finales del siglo XIX. Reflexiones desde una perspectiva de género." En Revista Iberoamericana de Educación, 45 (2), 1-13. Recuperado de: https://rieoei.org/RIE/article/view/2142

BARRANCOS, Dora. (2010). "La vida cotidiana", en: Nueva Historia Argentina. El progreso, la modernización y sus límites (1880-1916). Buenos Aires: Ed Sudamericana.

CALANDRIA, Sol. (2017). "Madres criminales: aportes sobre el infanticidio y la criminalidad femenina bonaerense en clave sociodemográfica". En Población \& Sociedad, Vol. 24 (2), Pág. 5-31. Recuperado de: http://www.poblacionysociedad. org.ar/archivos/24/P\&S-V24-N2- Calandria.pdf

DAIN, Mariana (2009), "La tolerancia bajo sospecha: políticas de control social proactivo en la ciudad de Córdoba a fines del siglo XIX" en: Portail de investigaciones Horizontes y convergencias. Lecturas Históricas y Antropológicas sobre el Derecho, Córdoba.

DAVIS, Ángela. (2017). Son obsoletas las prisiones?. Córdoba: Bocavulvaria Ed.

DE LAURETIS, Teresa. (1996). "La tecnología del género". En Mora. Revista del Área Interdisciplinaria de Estudios de la Mujer, 2, Pág. 6-34. Recuperado de: http://genero. institutos.filo.uba.ar/sites/genero.institutos.filo.uba.ar/files/revistas/adjuntos/Mora2.pdf

DE LAURETIS, Teresa. (2000). Diferencias. Etapas de un camino a través de la diferencia. Madrid: Horas y Horas.

DIAS DUARTE, Luiz F.., et al. (2006). "Família, reprodução e ethos religioso: subjetivismo e naturalismo como valores estruturantes." en Família e Religião. L. F. Diaz Duarte, M. L. Heilborn, M. L. d. Barros and C. Peixoto. Rio de Janeiro, Contra Capa Livraria.

FEDERICI, Silvia. (2011). Calibán y la bruja: mujeres, cuerpo y acumulación originaria. Buenos Aires: Tinta Limón.

FEDERICI, Silvia. (2013). La revolución en punto cero: trabajo doméstico, reproducción y luchas feministas. Madrid: Editorial Traficantes de sueños.

FEMENIAS, María Luisa y ROSSI, Paula Soza. (2009). "Poder y violencia sobre el cuerpo de las mujeres". En Sociologias, № 21, Pág. 42 - 65. doi: 0.1590/S151745222009000100004 
FOUCAULT, Michel. (2002). Vigilar y Castigar. Buenos Aires: Siglo XXI editores

FOUCAULT, Michel. (2008). Historia de la Sexualidad.1. La Voluntad de Saber. Buenos Aires: Siglo XX editores.

GARLAND, David. (2010). Castigo y sociedad moderna. Un estudio de teoría social. Buenos Aires: Editorial Siglo XXI.

HALPERIN, Paula y Acha, omar (2000). Cuerpos, géneros e identidades. Estudios de género en Argentina. Buenos Aires: Ed. Del Signo

LAGARDE, Marcela. (2005). Los Cautiverios de las mujeres: madresposas, monjas, putas, presas y locas. Ciudad de México: UNAM.

LOBATO, Mirta. (2007). Historia de las trabajadoras en Argentina. Buenos Aires: Edhasa.

MARITANO, Ornella y DEANGELI, Melina (2015)“Un proyecto correccional femenino. Universo social y lógica institucional de la Cárcel del Buen Pastor, Córdoba 18921910", en Anuario de la Escuela de Historia Virtual, Año 6, № 7.

MARTINETTI, María Laura. (2013). “El discurso jurídico sobre el caso Romina Tejerina: una mirada en clave de género." En Punto Género, №3, Pág. 221-241. Recuperado de: https://revistapuntogenero.uchile.cl/index.php/RPG/issue/view/2893

MENDOZA ESKOLA, Juanita (2016) “La crítica feminista al derecho: De la lucha por la igualdad al cuestionamiento de la identidad como ideal normativo", en Revista luris, Número 15(1), 2016.

NASH, Mary. (1993). "Identidad de género, discurso de la domesticidad y la definición del trabajo de las mujeres en la España del siglo XIX" , en: Perrot, Michelle y Duby, George (Dir.) (1993), Historia de las mujeres, Tomo IV. Madrid: Editorial Taurus.

OSZLAK, Oscar (2008) La formación del Estado-Nación Argentino. Orden, progreso y organización nacional. Buenos Aires: Ariel

PEGORARO, Juan (1994), "Teoría social, control social y seguridad. El nuevo escenario de los años 90"; en: Cuadernos de Posgrado de la UBA (1994), Buenos Aires.

PITCH, Tamar (2010) "Sexo y género de y en el derecho: el feminismo jurídico", en Anales de la Cátedra Francisco Suárez, 44 (2010)

PUIGGRÓS, Adriana. (2003). Qué pasó en la educación argentina. Breve historia desde la conquista hasta el presente. Buenos Aires: Galerna. 
RUGGIERO, Kristin. (1994). “Honor, maternidad y el disciplinario de las mujeres: Infanticidio en el Buenos Aires del siglo XIX". En Fletcher, L. (comp.), Mujeres y cultura en la Argentina del siglo XIX, (pp. 227-235). Buenos Aires, Argentina: Feminaria.

SALGUERO, Florencia y LETHINEN, Paola. (2017). Control, vigilancia y regeneración: la reglamentación de la prostitución en Córdoba (1900-1938). Trabajo Final de Licenciatura en Historia. Córdoba.

SALVATORE, Ricardo. (2010). Subalternos, derechos y justicia social. Ensayos de historia social y cultural argentina 1829-1940. México: Gedisa.

SANCHEZ, Mariana (2009). "La crítica feminista al discurso jurídico (o de cómo entender al Derecho como un ámbito de lucha por la igualdad de género)", en Anuario del Centro de Investigaciones Jurídicas y Sociales XII, 2009. Córdoba: Ferreyra

SCOTT, Joan. (2008). Género e Historia. México: Fondo de Cultura Económica.

SCOTT, Joan. (2011). "Género: ¿Todavía una categoría útil para el análisis?", en: La manzana de la discordia, Vol. 6, Enero-Junio 2011.

SMART, Carol. (2000). “La teoría feminista y el discurso jurídico.” En El Derecho en el Género y el Género en el Derecho. Buenos Aires: Biblós.

TREBISACCE, Catalina. (2016). “Una historia crítica del concepto de experiencia de la epistemología feminista." En Cinta moebio, N 57, Pág. 285-295. doi:10.4067/S0717554X2016000300004

VASALLO, Jaqueline. (2007). "Castas, honestas, viles y malas. La mujer en el imaginario jurídico de la América colonial." En Anuario X, del CIJS.Pág. 493-505 Recuperado en: . file://C:/Users/Garcia/Downloads/anuario_X.pdf

VIVEROS VIGOYA, Mara. (2008). "La sexualización de la raza y la racialización de la sexualidad en el contexto latinoamericano actual" en: CAREAGA, Gloria. Memorias del 1er. Encuentro Latinoamericano y del Caribe La sexualidad frente a la sociedad. México, D.F., http://www.ilef.com.mx/memorias\%20sexualidad.\%20lilia\%20 monroy.pdf

VIVEROS VIGOYA, Mara. (2016). "La interseccionalidad: una aproximación situada a la dominación" en: Debate Feminista, № 52, pág. 1-17. Mexico. Recuperado de: http://www.debatefeminista.cieg.unam.mx/wp-content/uploads/2016/12/ articulos/052 completo.pdf

YORNET, Cecilia. (S/D). "La odisea de venir de estados unidos a San Juan en el Siglo XIX: La historia de las maestras norteamericanas que trajo Sarmiento" recuperado de: http://www.sanjuanalmundo.org/articulo.php?id=17010 